\title{
Neonatal patient triggered ventilation
}

\author{
A GREENOUGH AND J POOL \\ Department of Child Health, King's College Hospital, London
}

SUMMARY Patient triggered ventilation was assessed in 14 neonates (gestational age 24-40 weeks). Inspiratory changes in airflow, monitored by a pneumotachograph, were used to trigger the ventilator and this was not associated with complications. Patient triggered ventilation was maintained for up to eight hours (mean duration five hours). In 13 of 14 infants oxygenation improved and this was associated in most with an increase in rate of delivered positive pressure inflations and inflating volumes. A greater improvement in oxygenation was shown when trigger mode was used during the recovery phase of respiratory distress syndrome. Only one infant, who made very little respiratory effort, failed to improve. We conclude that patient triggered ventilation may be used as an effective form of neonatal ventilation.

In a previous study we showed that patient triggered ventilation was feasible even in very preterm infants. ${ }^{1}$ We used oesophageal pressure changes to detect respiratory efforts and these pressure changes were then used to trigger the ventilator. In all infants this form of ventilation was associated with improvements in both inflating volume and oxygenation, as evidenced by transcutaneous monitoring. There was minimal interference from peristalsis. The major disadvantage, however, with using oesophageal pressure changes or abdominal movements (as has been done previously ${ }^{2}$ ) to detect respiratory efforts is the inability to differentiate correctly between obstructed and non-obstructed breaths. ${ }^{3}$ During an obstructed breath, which occurs as a result of a blocked endotracheal tube, respiratory efforts may continue and would be sensed either by changes in oesophageal pressure or abdominal movements despite the absence of airflow. Thus obstructed respiratory efforts can only be reliably detected as the absence of gas flow at the airway. The safest and most reliable trigger site, therefore, is likely to be flow changes at the airway. The present study investigated the practicality of using airflow changes as the patient trigger to a suitably modified ventilator.

\section{Patients and methods}

Fourteen infants were studied on 20 separate occasions, all were less than a week old and had a mean gestational age of 29 weeks (range 24-40 weeks). The infants had a variety of diagnoses: 11 had respiratory distress syndrome, one birth asphyxia, and two respiratory distress associated with severe prematurity-that is $<26$ weeks' gestation. These infants represented 14 consecutive babies ventilated on the neonatal intensive care unit. Infants were studied during the first neonatal week according to the availability of the trigger ventilator, thus they were at varying stages in their respiratory illness. Three of the 14 babies, all suffering from respiratory distress syndrome, were studied on three separate occasions during their respiratory illness.

Ventilatory support was by an SLE Newborn 250 ventilator. Ventilator settings were determined before the study by the clinical team caring for the infant; rates varied from $10-60 /$ minute, peak inspiratory pressures $15-26 \mathrm{~cm} \mathrm{H}_{2} \mathrm{O}$, inspiratory times were restricted to 0.5 seconds. ${ }^{4}$ No infant was paralysed or sedated, but those on ventilator rates less than $30 /$ minute were receiving treatment with a methylxanthine.

Infants were entered into the study once stable on conventional ventilation for at least 2 hours. They were then switched to continuous positive airways pressure (CPAP) trigger mode. Patient triggered ventilation was delivered by a modified SLE 250 Newborn ventilator. The ventilator has a manual breath control which in CPAP mode allows delivery of a single positive pressure inflation, of magnitude and duration conforming to that predetermined during intermittent positive pressure ventilation mode. An interface has been developed such that only if a critical change in inspiratory airflow $(>0.4 \mathrm{l} /$ minute $)$ is exceeded will the manual breath control be triggered (systems delay up to 40 milli- 
seconds can be experienced). The ventilator has also been modified so that after roughly eight seconds, if the sensor has failed to detect respiratory efforts of sufficient magnitude to trigger the ventilator, then a manual breath is delivered.

Airflow changes were monitored using a pneumotachograph (Mercury F10L) placed between the endotracheal tube and ventilator circuit. This device recorded flow, inspiratory flow changes triggered the ventilator. The pneumotachograph was attached to a Validyne pressure transducer (range $\pm 2 \mathrm{~cm}$ $\mathrm{H}_{2} \mathrm{O}$ ), the signal of which was electronically integrated by a Gould Integrator (model no 13-4615-70). The pneumotachograph was calibrated at the beginning and end of each study period, on no occasion did the characteristics of the pneumotachograph change. Oesophageal pressure changes were monitored using an oesophageal balloon and catheter system $^{5}$ attached to the Validyne pressure transducer (range $\pm 50 \mathrm{~cm} \mathrm{H}_{2} \mathrm{O}$ ). Ventilator pressure changes were monitored from the infant's side of the pneumotachograph (Validyne pressure transducer range $\pm 50 \mathrm{~cm} \mathrm{H}_{2} \mathrm{O}$ ).

Flow, volume, oesophageal and ventilator pressure changes were recorded simultaneously on a Polygraph (Gould model no 2800S). Recordings were made 20 minutes before starting trigger mode and during the initial 20 minutes on trigger mode. Arterial blood gases were checked from an indwelling arterial catheter 20 minutes before changing to trigger mode-that is, immediately before the connection of the pneumotachograph in the circuitthen 20 and 60 minutes later and subsequently as clinically indicated (at least every four hours) throughout the period of trigger ventilation. An arterial blood gas was again checked 20 minutes after discontinuing trigger mode. Throughout the period of ventilation the infants were continuously monitored either using a Searle intra-arterial electrode or a transcutaneous oxygen monitor (Draeger). If the transcutaneous monitoring showed oxygenation to be decreasing $(>1.33 \mathrm{kPa})$ an arterial blood gas was immediately checked, and if this confirmed the change, the infant was immediately returned to conventional ventilation. Otherwise trigger ventilation was maintained while one of the researchers (AG) was within the neonatal intensive care unit: the recording equipment rather than the ventilator required supervision.

The magnitude and rate of the infant's spontaneous respiratory efforts were assessed from the oesophageal pressure recording. By comparison of the oesophageal and ventilator pressure record it was possible to determine the infant's interaction to positive pressure inflation. ${ }^{67}$ Ventilator rate and inflating volume were calculated from the whole of the 20 minute recording before starting trigger mode and the initial 20 minutes on trigger mode and then expressed as the mean for each 20 minute period. To assess the effectiveness of trigger mode ventilation, ventilator rate, inflating volume, and arterial blood gases during the different modes of ventilation were compared.

Statistical analysis to assess if differences in the results using the two modes of ventilation were significant was performed by a paired Student's $t$ test.

Ethical permission for the study was granted by the hospital ethics committee.

\section{Results}

In most of the infants the delivered number of positive pressure inflations increased during the period of trigger ventilation $(p<0 \cdot 05$, see table) compared with conventional ventilation. The rate only decreased in one infant in whom trigger ventilation had to be discontinued after 20 minutes due to a deterioration in oxygenation (from $8.66 \mathrm{kPa}$ to $5.47 \mathrm{kPa}$ ). The infant ( 24 weeks gestational age) had previously suffered bilateral grade IV intraventricular haemorrhages and had made very little spontaneous respiratory effort. Delivery of positive pressure inflation decreased from 20 to 8-12 breaths/ minute during trigger mode $(8$ breaths/minute was the maximum rate delivered by the ventilator in apnoea mode).

Delivered volume remained constant or increased during trigger mode $(\mathrm{p}<0 \cdot 02$, see table). Respiratory efforts during trigger mode were synchronous. Improved volume exchange on trigger mode was seen among the infants who were actively expiring during conventional ventilation.

In 13 infants, during the first hour of trigger ventilation, oxygenation improved falling only in the infant who was apnoeic. Comparison of the results

Table Comparison of the two modes of ventilation. Results are mean (range)

\begin{tabular}{lll}
\hline & $\begin{array}{l}\text { Conventional } \\
\text { ventilation }\end{array}$ & $\begin{array}{l}\text { Trigger mode } \\
\text { after one hour }\end{array}$ \\
\hline Volume $(\mathrm{ml})$ & $6 \cdot 0$ & $6 \cdot 8$ \\
& $(2 \cdot 5-20)$ & $(4-20)$ \\
Ventilator rate & 46 & 55 \\
$\quad($ breaths/minute $)$ & $(5-70)$ & $(12-74)$ \\
$\mathrm{pH}$ & $7 \cdot 28$ & $7 \cdot 29$ \\
& $(7 \cdot 2-7 \cdot 4)$ & $(7 \cdot 2-7 \cdot 45)$ \\
$\mathrm{PaO}_{2}(\mathrm{kPa})$ & $9 \cdot 06$ & $10 \cdot 3$ \\
$\mathrm{PaCO}_{2}(\mathrm{kPa})$ & $(6 \cdot 67-12 \cdot 7)$ & $(8 \cdot 93-13 \cdot 9)$ \\
& $5 \cdot 47$ & $5 \cdot 73$ \\
& $(4 \cdot 27-6 \cdot 67)$ & $(3 \cdot 33-6 \cdot 40)$ \\
\hline
\end{tabular}


after one hour on trigger mode with those on conventional ventilation showed a significant improvement in $\mathrm{PaO}_{2}(\mathrm{p}<0.02$, see table). During a similar period there was no significant change in $\mathrm{pH}$ or $\mathrm{PCO}_{2}$. In one (25 weeks gestational age) of the 13 infants in whom oxygenation had improved and was maintained, a respiratory acidosis developed at two hours, and this was associated with a reduction in the number of triggered breaths suggesting a decrease in respiratory efforts. Among the other 12 infants the period of trigger ventilation continued for between three and eight hours (mean five hours). None of these infants developed a respiratory acidosis and oxygenation was maintained. Trigger ventilation was discontinued for other intensive care procedures to take place, due to the inconvenience imposed by the size of the recording equipment.

Three infants were studied on three separate occasions during their respiratory illness within the first week of life. On all three occasions trigger mode ventilation was associated with an improvement in oxygenation, but this was greater during the recovery phase of respiratory distresss syndromethat is, when the infants had been on conventional ventilation at ventilator rates less than 30 breaths/ minute. In total, excluding the infant on trigger mode for only 20 minutes, on eight occasions infants were studied who had previously received rates less than 30 breaths/minute, and on 11 occasions infants were studied who had been on rates in excess of 55 breaths/minute. Comparison of the change in oxygenation after one hour on trigger mode between these two groups showed that the infants receiving a slower rate of conventional ventilation had a significantly greater change in oxygenation (mean $2.67 \mathrm{kPa}$, range $2 \cdot 13-3.07 \mathrm{kPa}$ ) than those previously ventilated in excess of 55 breaths $/$ minute $(0.93 \mathrm{kPa}$, range $0.67-1.47 \mathrm{kPa}), \mathrm{p}<0.02$.

\section{Discussion}

One of the aims of our investigation was to study this form of ventilation in a consecutive series of infants to assess its usefulness as a general mode of ventilation. Although most of our patients suffered from respiratory distress syndrome other diagnoses were included and we found patient triggered ventilation to be useful in most (13 of 14) - that is, oxygenation improved.

The results confirmed our previous findings that even very preterm infants show spontaneous respiratory activity during artificial ventilation and thus are capable of triggering the ventilator. ${ }^{8}$ Our findings do, however, suggest that patient triggered ventilation may have only limited success in very preterm infants previously receiving 'full' conven- tional ventilation, as evidenced by the results of the two most immature infants (24 and 25 weeks gestational age) included in our study. In one, suffering from bilateral grade IV intraventricular haemorrhages, oxygenation fell due to a lack of respiratory efforts and the second, after two hours, developed a respiratory acidosis.

The SLE ventilator in trigger mode incorporates an apnoea alarm, this ensures delivery of inflating pressures after roughly eight seconds. If an infant is apnoeic or with minimal respiratory efforts positive pressure inflation will only be delivered at a rate of $7-8$ breaths/minute. This was insufficient to maintain oxygenation in the apnoeic infant included in our study. A more effective method of compensating for apnoeic periods would be for a minimum number of ventilator breaths/minute to be predetermined and if these were not triggered, they would be delivered automatically.

In all infants triggered ventilator breaths were only delivered at the beginning of inspiration ensuring synchronous respiration with ventilation, which is advantageous. ${ }^{9}$ Detection of respiratory efforts by airflow changes also ensured that all apnoeas and episodes of blocked endotracheal tubes were correctly detected. There are, however, two theoretical problems that could be encountered when using a pneumotachograph sited in the airway as trigger site. Firstly, the pneumotachograph used is unheated and during prolonged use could be affected by condensation, but it is used inside the heated incubator. The characteristics of the pneumotachograph were studied at the beginning and end of any study periods, and they remained unaltered. This lack of change in the resistance of the pneumotachograph suggested condensation had not been a problem. Secondly, the pneumotachograph, by increasing dead space, may lead to increased respiratory efforts and respiratory acidosis. In this study, however, although infants were ventilated up to a maximum of eight hours, only one infant developed a respiratory acidosis. It should be noted, however, that although oxygenation improved after insertion of the pneumotachograph, carbon dioxide concentrations did not decrease during the first period of trigger ventilation despite the increase in minute volume. Subsequent arterial blood gases, despite maintenance of the pneumotachograph in the circuit, however, did not show increasing carbon dioxide concentrations; this suggested that the infant had accommodated to the increase in dead space, and in the absence of a respiratory acidosis, without important complications. Unfortunately, no infant was studied for longer than eight hours, as the recording equipment to which the pneumotachograph was attached could not be left unsupervised. 
It is obviously now important to test the long term effectiveness and possible side effects of this form of patient triggered ventilation using a pneumotachograph in the airway. As a consequence the patient triggered system has now been modified to consist only of a pneumotachograph and transducer directly attached to the ventilator and the effect of long term patient triggered ventilation is now being studied.

Infants were included in this study at varying stages of their illness, both during the acute and recovery phase. As the length of ventilation was restricted in each individual baby, however, it is not possible to comment on the suitability of this form of ventilation throughout the respiratory illness. Our results do suggest that it is more effective during the recovery phase. The greater improvement in oxygenation at this time is possibly due to the increased number of delivered positive pressure inflations, as had been seen previously. ${ }^{1}$ This increase may reflect an increase in respiratory efforts due to the use of methylxanthines during the recovery phase, which facilitated triggering. ${ }^{10}$ This means that using the present system weaning during trigger mode can only be achieved by reducing pressure rather than rate of delivery of positive pressure inflations.

Although all infants with respiratory efforts were converted to synchronous respiration and none developed an air leak during trigger mode, as no long term studies were performed we cannot comment whether this form of ventilation would reduce the need for paralysis or alter the incidence of pneumothoraces.

We conclude that patient triggered ventilation is safe and effective in the short term among infants who show respiratory efforts, and it may be advantageous as it is associated with improvements in oxygenation. The practicality and effectiveness of patient triggered ventilation using airflow changes throughout the course of a variety of neonatal respiratory illnesses is now being investigated.

Sister J Pool is supported by Children Nationwide Medical Research Fund. The equipment for this study was generously provided by Specialised Laboratory Equipment (SLE) Ltd and Children Nationwide Medical Research Fund. We thank Mrs Angela McPherson for secretarial help.

\section{References}

${ }^{1}$ Greenough A, Greenall F. Patient triggered ventilation in premature neonates. Arch Dis Child 1988;63:77-8.

2 Mehta A, Callan K, Wright BM, Stacey TE. Patient triggered ventilation in the newborn. Lancet 1986;ii:17-9.

${ }^{3}$ Southall DP, Richards JM, Lau KC, Shinebourne EA. An explanation for failure of impedence apnoea alarm systems. Arch Dis Child 1980;55:63-5.

${ }^{4}$ Greenough A, Greenall F, Gamsu HR. Inspiratory times when weaning from mechanical ventilation. Arch Dis Child 1987;62: $1269-70$.

${ }^{5}$ Greenough A, Morley CJ. Oesophageal pressure measurements in ventilated preterm babies. Arch Dis Child 1982;57:851-5.

${ }^{6}$ Greenough A, Morley CJ, Davis JA. The interaction of spontancous respiration with artificial ventilation in preterm babies. J Pediatr 1983;103:769-73.

${ }^{7}$ Greenough A, Wood S, Morley CJ, Davis JA. Pancuronium prevents pneumothoraces in ventilated premature babies who actively expire against positive pressure inflation. Lancet 1984 ;i: $1-4$.

${ }^{8}$ Greenough A, Morley CJ, Davis JA. Respiratory reflexes in ventilated premature babies. Early Hum Dev 1983;8:65-75.

${ }^{9}$ Greenough A, Pool J, Greenall F, Morley C, Gamsu H. Comparison of different rates of artificial ventilation in premature neonates with respiratory distress syndrome. Acta Paediatr Scand 1987;76:706-12.

10 Greenough A, Elias-Jones A, Pool J, Morley CJ, Davies J. The therapeutic effects of oral theophylline in preterm ventilated infants. Early Hum Dev 1985;12:15-22.

Correspondence to Dr A Greenough, Department of Child Health, King's College Hospital, Denmark Hill, London SE5 8RX.

Accepted 11 November 1987 